\title{
A complete database of international chess players and chess performance ratings for varied longitudinal studies
}

\author{
ROBERT W. HOWARD \\ University of New South Wales, Sydney, New South Wales, Australia
}

\begin{abstract}
Chess is an oft-used study domain in psychology and artificial intelligence because it is well defined, its performance rating systems allow easy identification of experts and their development, and chess playing is a complex intellectual task. However, usable computerized chess data have been very limited. The present article has two aims. The first is to highlight the methodological value of chess data and how researchers can use them to address questions in quite different areas. The second is to present a computerized database of all international chess players and official performance ratings beginning from the inaugural 1970 international rating list. The database has millions of records and gives complete longitudinal official performance data for over 60,000 players from 1970 to the present. Like a time series of population censuses, these data can be used for many different research and teaching purposes. Three quite different studies, conducted by the author using the database, are described.
\end{abstract}

Chess has been an oft-used research domain in psychology and artificial intelligence (Charness, 1992) for several reasons. The domain is well defined; its quantitative performance rating systems allow easy identification of experts and their development; real-world longitudinal data are available; and chess playing is a complex intellectual task. PsycINFO lists about 200 papers with chess in the title, by psychologists who have used chess data for various research purposes. Some have aimed to understand chess performance itself, others have generalized findings from one obviously intellectual task to others (see, e.g., van der Maas \& Wagenmakers, 2005). Indeed, Newell (1973) dubbed chess a "drosophila" for cognitive psychology.

\section{Some Illustrative Examples of Research Studies Using Chess Data}

A variety of findings in psychological studies have been based on chess data. Atherton, Zhuang, Bart, Hu, and He (2003) examined patterns of brain activation during chess playing. Burns (2004) looked at speed and chess performance. Some researchers have examined the psychometric abilities involved in chess (see, e.g., Gobet, de Voogt, \& Retschitzki, 2004). Some research suggests, for instance, that visuospatial ability, particularly the ability to manipulate visual representations, is important for chess performance (Frydman \& Lynn, 1992). Chess imagery seems to differ according to skill level (Milojkovic,

The author thanks Herman Lukito for his valuable help in starting this database project, as well as the many individuals and chess federations who contributed data. Send reprint requests to R. W. Howard, School of Education, University of New South Wales, Sydney, NSW 2052 Australia (e-mail: rwh@unsw.edu.au).
1982; Saariluoma, 1991), and concurrent visuospatial tasks interfere strongly with intake of chess information (Saariluoma, 1992). Waters, Gobet, and Leyden (2002) reported little relation between chess skill and a measure of visual memory, the Shape Memory Test, but they also noted that the ability to manipulate visual images (which unfortunately was not gauged in their study) may be much more important.

Chess has been particularly useful for the study of expertise. Researchers have examined the development and possible decline of high performers, with findings often generalizing to many other domains. Perhaps the best-known research thread has focused on what chess experts know that allows them to outperform novices. De Groot (1965) reported that experts "chunk" chess pieces on the board into familiar patterns, a finding later replicated by Chase and Simon (1973). These well-organized "chunks" of domain-specific knowledge aid recall and analysis of chess positions and suggest courses of action (see, e.g., Holding, 1985). This general finding has been replicated in many other domains, such as go, dance steps, and computer programming (Howard, 1995; Reitman, 1976). Charness, Krampe, and Mayr (1996) studied the effects on chess performance of age, coaching (which apparently had little effect), and amount of practice. Charness, Tuffiash, Krampe, Reingold, and Vasyukova (2005) also looked at the link between amount of practice and expertise. Charness and Gerchak (1996) aimed to relate some well-known differences in proportions of top chess performers by sex and nationality to differing national participation rates.

Chess also has been useful for studying other phenomena in varied areas. For instance, Howard (1999, 2001) used chess data to examine interpretations of the Flynn effect, essentially comparing the performance of younger 
and older players over several decades. Schwarz, Schachinger, Adler, and Goetz (2003) used chess play to look at the link between heart rate and various mental states. Elo (1965), using a very small sample of grandmasters, looked at intellectual aging. He found that the peak chess performance age is about 35 years old; performance may decline thereafter because overall chess skill is a race between a player's decreasing fluid intelligence after age 20 and increasing domain-specific knowledge with experience. Howard (2005b), with a much larger sample, confirmed Elo's (1965) estimate of the peak performance age.

\section{A Major Difficulty With Using Chess Data for Research}

As the studies above show, chess is a domain with many potential uses for psychologists. However, researchers wishing to use chess data often have faced a grave problem that has limited their research possibilities: Usable, computerized, longitudinal chess data are relatively scarce. Various national chess federations run performance rating systems, but the data often are computerized only for recent years. For instance, the United States Chess Federation (USCF) rating system began in 1950, but the data only are computerized from 1977. Because of hardware and software changes, the computerized data are also usable only from much later, according to a USCF spokesperson (personal communication). Official ratings data of the international chess federation (FIDE) are computerized only from 1990, and these computerized files have problems, as described below. Howard (1999) used FIDE data from 1970 but could only access pre-1990 official FIDE data from printed volumes of the periodical Sahovski Informator ("Chess Informant"). Because of resource constraints, top-10 and top-50 player data could only be sampled every 3 years, and many other issues could not be tackled at all.

\section{A New FIDE Database to Solve This Problem}

However, this problem is now partially solved. The author has computerized all official FIDE ratings data since the inaugural 1970 list, creating a consistent database for the entire time span from that date to the present, and has tested this database by using it for three major studies in different domains.

The database has potential uses for research in many areas, as well as for the teaching of research methodology. In general, computations with a large database can yield many useful inferences. Consider, for example, a database containing the name and address of everyone in a town. On the basis of these data, one can derive much more useful information, including who lives with whom, average household size, typical household types, and so on.

The chess database has many advantages for researchers. First, the official performance ratings data are relatively objective. Second, real-world data of an entire population (i.e., all international chess players) are available over a range of several decades. Thus, there is no concern about sampling bias in these data, and no need for inferential statistics. Third, international chess is a meritocracy. Stud- ies of high performance in many other domains, such as science, can be difficult to interpret because, for example, talent, amount of practice, and motivation often are confounded with variations in opportunity. In chess, though, talent can readily rise, however unpopular or unconnected a player may be. Expertise development and other phenomena can therefore be studied in an environment with little influence of gatekeepers and no glass ceiling. Fourth, the data already have been collected, so the most expensive and difficult part of most research projects can be avoided completely.

\section{Aims of the Present Article}

The present article has two major aims. The first is to highlight the methodological value of the domain of chess to researchers and to encourage greater use of chess data to study a wide variety of research problems. The second aim is to describe the FIDE database and its limitations, how to access and use it, and how to combine its use with other sources of chess data.

\section{ORGANIZED CHESS}

Chess is one of the world's most popular games, and some nations class it as a sport. FIDE was founded in 1924, and currently it has about 160 member national chess federations. In 1999, the International Olympic Committee recognized FIDE as an international sports federation, and FIDE hopes eventually to insert chess into the Olympics. Chess is very well organized. Many nations have national and provincial chess associations, and many run national rating systems - for instance, the United States, the United Kingdom, Australia, New Zealand, and Canada. Chess also has a very large literature (Graham, 1984).

Male and female players once competed in largely separate tournaments, as in tennis. Today, however, most chess competitions are mixed.

\section{The FIDE Rating System}

Chess performance rating systems date back to the 1920 s, when they were used by U.S. correspondence players playing by mail. An early national rating list was devised by Kenneth Harkness for the USCF and appeared in the December 1950 issue of the popular magazine Chess Life. This list was based on all USCF games in the previous 30 years and listed about 2,000 players. In it, all players were given numerical ratings on a scale that could go up to about 3000. A player lost or gained rating points after each game, according to the result and the opponent's rating. After a number of games, the rating was a rough measure of a player's current playing strength (Elo, 1986). In 1959, the USCF asked a committee chaired by Arpad Elo to revise the system to overcome such anomalies as a player winning all games in a tournament but still losing rating points (Elo, 1986). Glickman (1995) and Elo (1986) describe in detail the issues surrounding chess rating systems.

The first FIDE rating list is dated December 1970 and was based on games in international tournaments in ap- 
proximately the previous 2 years. As mentioned, FIDE now has computerized ratings only from 1990; rating lists for 1970-1989 were published only in printed volumes of Sahovski Informator. Some pre-1990 lists are now available on CD as image files of the original Sahovski Informator pages (Mantanovic, 2000). The early FIDE lists give player surname, current performance rating, nationality, and title (e.g., grandmaster). Later lists give first name initials and, from July 1985, number of games played in each rating period. From 1990, the lists give birth dates for most players. The pre-1975 lists have only a few female players; in 1975, a separate women's list was issued, and some years later the male and female lists were combined. FIDE added 100 points to all female ratings in 1987, except for that of one player, Zsuzsa Polgar, evidently to bring them into line with male ratings. A new list was issued once a year until 1978, then twice a year until 2000 , thrice in 2000 itself, and thereafter four times a year. The rules for getting and staying on the list have altered. For instance, until 1993 male players needed a minimum rating of 2200. Inactive players may be dropped from the list. FIDE now publishes a new computerized list every three months on its Web site, www.fide.com.

FIDE awards six performance-based master titles; three are open to all players, and three are available for women only. Two open titles, grandmaster (GM; most prestigious) and international master (IM; second most prestigious), predate the rating system, and criteria for awarding them have varied over the years. The third open title is FIDE master (FM; least prestigious) and was introduced in 1979, with its holders first designated in the 1980 list. Each of the titles has a female-only counterpart, with easier criteria than the open version: woman's grandmaster (WG), woman's master (WM), and woman's FIDE master (WF). Ten women currently hold the open GM title.

\section{THE FIDE DATABASE}

\section{Creating the Database}

The author created the FIDE database by pooling the computerized lists and by typing pre-1990 lists by hand into a computer from printed volumes of Sahovski Informator. The project took much longer than expected because the official FIDE ratings data are something of a mess; any single list may seem fine, but putting several together and tracing trends exposes many problems. Indeed, the problems of administering a large list of names of persons from many different nations are well known. Different individuals can have the same name (e.g., Wolfgang Schmidt), name spellings change, and names change upon marriage or by deed poll. Governments that administer large lists of names such as electoral rolls know the difficulties well, and many deal with the problems by assigning all citizens a unique, permanent identifier. FIDE administration of the rating system data, on the other hand, has perhaps been sloppy at times.

Pre-1990 lists in Sahovski Informator have limitations and errors. Some players are hard to identify and to track over time because only surnames are given in the early lists. Also, name spellings continually change, especially when converted from one alphabet to another (e.g., Sakharov may become Sacharov or Zakharov). First and second names sometimes are inverted, and prefixes are used inconsistently (e.g., de Caro may become Caro). Spanish names sometimes are given only in part and then change, so that Juan José López Martínez may be Martínez in one list and López in another. Upon their marriage, female players sometimes gain double-barreled names but often do not, making them hard to trace. However, many players can be identified and traced through by matching nationality, titles, ratings, and so on, and by comparing information with that in O'Connell (1976) and Gaige (1987). The first computerized 1990 list gives initials of players from many years back, which has also helped with identification.

FIDE's post-1990 computerized files also have many errors. Players are mixed up, especially when they have identical names. Players also sometimes are listed twice in a single list, with different name spellings and ratings; for instance, a female player getting married may be listed under her maiden and new names, with different ratings. The main reason for these problems is that FIDE committed the cardinal sin of database design: not having a unique, permanent ID for each player. Players do have ID numbers, but these seem to be country coded. When a player shifts nations, the player's ID may change, as may the ID of a female player on marriage. Some IDs change over time for no obvious reason at all. As a result, the same player in different lists may have as many as four different IDs. Female players in particular are difficult to trace over time, but the top-rated ones are easily identifiable.

The author ran computerized post-1990 data through a special matching program, then checked the data for consistency as much as possible. FIDE lists the birth dates of many but not all players, so many birth dates in the database were taken from the FIDE files. Others were taken from Gaige (1987) and the ChessBase Players Encyclopedia, and in some cases by contacting the player or his or her national chess organization. Not all birth dates have been obtained, and some show inconsistencies across the FIDE files. In a few cases, only the year of birth is known, and in these cases the month and day of birth were set at January 1 .

Doubtless many errors remain, and the final product should be seen as a somewhat messy approximation. Real-world data usually are messy, and the database always should be used with this caution in mind. However, it is fine for large aggregate calculations and for dealing with all players in the top 500 ranks in each list, who usually are readily identifiable. The database will undergo continuous improvement, as more anomalies are detected and corrected.

\section{Access to and Description of the FIDE Database}

The database is in Microsoft Access format. Using it requires a basic knowledge of Access queries. Because it is impossible to anticipate all possible uses, only three preset queries are included to illustrate the use of the data- 
base. The file is over 100 megabytes in size, and it can be downloaded using the following information: URL: http://education.arts.unsw.edu.au/FIDEBasehome
.htm

User name: FIDEBase

Password: Suldrak3Xnam2

These fields are all case sensitive.

The database is relational, with two tables ("Players" and "Ratings/Ranks/Titles") linked by ID number. Each player has a unique ID number, either FIDE's current ID or one assigned by the author for players who fell off the list before 1990. The Players table has six fields: IDNumber, LastName, FirstName, Sex, DOB (date of birth), and FirstonList (the earliest list a player is on). The Ratings/Ranks/Titles table has seven fields: IDNumber, Title, Country, Rating, Games, RatingDate, and Rank. RatingDate refers to the date a particular list came out, and Rank is the individual's position within that list according to rating (e.g., the top rating in the list is 1 , and the 10th highest rating is 10). In the event of a tie (e.g., five players in 10th rank), all are assigned the same rank (e.g., $10)$. In the Games field is the number of games played in the period covered by a given list. A player's title and country may change from list to list, and there are some inconsistencies across lists for some players. Only the highest title awarded is given in the list. Another complication is FIDE's handling of female titles. Until 2004, only the most prestigious female title is listed in the Title field, even if that player also held a more prestigious open title; for some women, their most prestigious title is included in the FirstName field. For instance, if a female player held both GM and WGM titles, only the WGM title would be listed in the Title field, and her GM status would be given only in the LastName field. However, from 2004, the most prestigious title is listed in the title field.

Titles are abbreviated in the Title field according to FIDE convention: $\mathrm{g}=$ grandmaster, $\mathrm{m}=$ international master, $\mathrm{fm}=$ FIDE master, $\mathrm{wg}=$ woman's grandmaster, $\mathrm{wm}=$ woman's master, $\mathrm{wf}=$ woman's FIDE master. All dates are in day/month/year format.

The database is updated continually, and the Web page above specifies the date of the last update.

\section{Illustrative Uses of the Database for Researchers}

The first preset query generates all data for Australian female players. The second generates all data for a single player (Garry Kasparov). The third generates the 1970 rating list.

From the two tables, many additional data can be derived. For instance, to get the top 50 players in a given list, one would do a select query on RatingDate and Rank. To generate a list of all grandmasters, one would do a select query on the Title. To compute the average number of rated games and years to become a grandmaster, one could perform the same select query for grandmasters and then derive the values.

The author has used the database for three major studies, which further illustrate its use. Howard (2005b) compared younger and older players over several decades, to study interpretations of the Flynn effect. The study involved computing the average age of top players over the span of the lists. Top players were getting younger, which may or may not be due to increasing population ability. Computations with the database allowed several alternative explanations of this age effect, such as players getting more practice, to be excluded.

Howard (2005a) examined whether the many societal changes in the last few decades in the roles and opportunities for women have reduced the male preponderance in chess. Recall that there is no glass ceiling in the chess world. The study involved first comparing male and female performance ratings from 1975 for the top 10, 50, and 100 players and for all players, and then looking at the distributions of male and female ratings on the latest available list. These data suggested little convergence in performance since 1975. Then, number-of-games data from 1985 were used to examine career patterns for any explanations of the difference in performance. These data suggested that women have much shorter chess careers and play many fewer rated games. One explanation for the male/female difference may thus be that chess is more of a passing interest for women.

The third use was a detailed study of the demographics of international chess players and various performance records. Some data from this study appeared in a cover story in Chess Life (Howard, 2004).

\section{Proposed Additional Uses for Researchers}

The database has many possible uses. For instance, the chess data are analogous to a time series of population censuses. Researchers from very different fields can do many different studies with census data, depending on their interests and ingenuity. This section lists only some possible studies to illustrate the database's versatility.

As mentioned, Elo (1965) studied cognitive aging with a small sample of grandmasters. The database can provide a much larger sample for determining the effects of such variables as amount of practice and demographics on aging. Amount of practice can be measured from the number of rated games, though in fact these internationally rated games may be just a fraction of those actually played. Career length can be determined from the numberof-games data that begin in 1985. Careers finish when a player's number of games drops to zero and stays there.

Many aspects of expertise can also be studied. The database can be used to identify samples for further research. For instance, one can study the role of motivation. Why do some players quit early and others persist? Is this difference due to a series of failures, such as game losses? Ratings data may give clues. What motivational characteristics do those at the very extremes of expertise have, and what are the motivational differences between males and females at the extremes? Samples can be identified and studied further by contacting the individuals. Some grandmasters have Web sites, and other players can be contacted through their national chess federations.

The psychometric abilities involved in chess need much more research. One school of expertise development 
maintains that amount of practice is the major determinant of high performance in a domain such as chess. As mentioned, some researchers have highlighted the importance of visuospatial ability, whereas others have downplayed its importance or even that of general intelligence (Barrett, 2002; Gobet et al., 2004). A large-scale study of grandmaster IQ scores and more specific abilities is needed to address these issues, and using the database, samples for such research could be identified.

Another possible use is in the study of twins. How do their performance ratings and career patterns compare? The author tried to identify twin pairs with a select query on last name and birth date, but in this context the limitations of official FIDE data became apparent. Many possible pairs emerged via the query, but at least some seemed to be the same player with different name spellings and IDs. However, a trawl through the pairs to eliminate errors should yield a provisional list of twins. Then, their chess federations could be contacted to determine which actually are twins and whether they are fraternal or identical.

Another possible use would be to run a data-mining program through the database.

\section{Uses for Teaching Research Methodology}

The FIDE database also can be used to train students in research methodology, since it allows students to work with easily accessible, interesting, real-world longitudinal data for an entire population. Instructors may set specific research exercises (e.g., what is the average career length and game total?) or give more general questions for students to tackle. Students may be asked to devise their own research questions and carry out their own potentially publishable studies.

At a more elementary level, the database can be used to train students in the use and understanding of descriptive statistics with very large numbers of cases and real-world data. Students could calculate distributions, means, and standard deviations of ratings data in entire rating lists, for instance. They could also take random samples of varying sizes and compare the sample data statistics with those of the entire population.

\section{Limitations of the Database}

Real-world data usually are messy and should be used with some caution. Even oft-used national population census data can be filled out carelessly and/or falsely, despite threatened official penalties. In the 2001 Australian census, for example, 70,509 persons (about $0.37 \%$ of all respondents) declared their religion as "Jedi," despite a government warning about penalties for doing so.

Some specific limitations and problems of the FIDE database were mentioned earlier, and a few more are given here. The algorithm used to compute ratings has been criticized (see, e.g., Glickman, 1995). There have been a few cases of rating fraud, with players allegedly rigging tournaments to inflate their ratings. FIDE disavowed the very high ratings of some players from Myanmar a few years ago, for instance, after accusations of fraud. Another player had a grandmaster title removed after fraud accusa- tions. Top players may also protect high ratings by avoiding weaker tournaments in which they could lose rating points.

FIDE also has been accused of sloppy administration of the rating system in the last decade or so. Every new FIDE list reveals duplicate entries for the same player and longstanding players given a new ID for no apparent reason at all. FIDE has allowed ratings inflation of about 100 points at the top since the 1980s, and some studies may need to correct for this inflation. The number-of-games data in 2003 also are suspect, since they seem very low in comparison with other years and may underreport the actual number. The July 1997 list overall seemed to have a particularly large number of errors, such as many players who had different IDs than in previous lists. The author tried to correct as many of these errors as possible, but doubtless many remain. As mentioned, the database can undergo continuous improvement as anomalies are corrected.

\section{OTHER SOURCES OF CHESS DATA}

The database can be used in combination with other sources of chess data. The Internet has many useful chess Web sites; for instance, most national federations have Web sites, sometimes with their own national ratings data.

The German company ChessBase publishes a very useful data source in its flagship ChessBase 9.0 program. This has millions of games going back centuries and a Players Encyclopedia. The latter gives much demographic information on players and an FIDE "rating profile" based on the same data sources used in the present study. Unfortunately, the rating profiles usually only cover a limited period and have many errors. The profiles only date back to 1976 , and even much later with some players who came on the list earlier than indicated. Players are conflated, and some players are listed twice under different names. These profiles should not be used for research. The Encyclopedia has limited database functions, but it cannot do aggregate calculations; the user mostly can only generate selective lists (e.g., all title holders, all Nigerian players, all females, or all Nigerian male title holders).

Various printed reference works do give some data, such as various records and some player details (e.g., Burgess, 1999; Divinsky, 1990; Gaige, 1987; O'Connell, 1976; Sunnucks, 1976; Whyld, 1986). The already-mentioned CD by Mantanovic (2000) has many historical data, including details of key tournaments, matches, and events.

Jeff Sonas has a Chessmetrics Web site with lists of top players going well back into the 19th century. His rating calculation algorithm is different from FIDE's, however. Sonas provided some useful data for the author (given in Howard, 2005b) on the ages of top-10 players going back to 1880 . The URL for this site is www.chessmetrics.com.

Finally, chess-playing computer programs now play extremely well and can beat all but the very best humans. They have been used for various research purposes and can be used for some psychological studies (e.g., Chabris \& Hearst, 2003). Games have been recorded for centuries, and present and past levels of human chess skill were 
directly compared by British mathematician John Nunn (1999). He showed that top-level chess has become much more intellectually demanding. Using the computer program Fritz to scan games for serious errors, he compared players' performance in two top-level tournaments at either end of the 20th century: Carlsbad, 1911, and Biel, 1993. Both tournaments had many of their era's top players. Skill level was very much higher in 1993, and Nunn concluded that the 1911 tournament would be considered weak today. This finding has implications for interpretations of the Flynn effect (Howard, 2005b).

\section{DISCUSSION}

The present article has focused on chess, but data from other intellectual games, such as bridge, go, and backgammon, also are available. However, such data often are much more limited than those for chess (Howard, 2001). Some research has looked at bridge and go expertise, and data from these games might also be mined for other psychological research purposes.

Finally, as mentioned earlier, the official FIDE ratings data have many problems. The author has spent countless hours trying to eliminate errors, but doubtless many remain. The database should be used with some caution and all data from it treated as approximations. No theory of psychology, for example, should stand or fall according to whether a study value from the database is 1.1 or 1.4 . The database could be useful when used in conjunction with other data and with large aggregate calculations, but all published studies using it should carry a warning about its limitations.

\section{REFERENCES}

Atherton, M., Zhuang, J., Bart, W. M., Hu, X., \& He, S. (2003). A functional MRI study of high-level cognition: I. The game of chess. Cognitive Brain Research, 16, 26-31.

Barrett, L. (2002). Do chess and go need "g"? Trends in Cognitive Sciences, 6, 499.

Burgess, G. (1999). Chess highlights of the 20th century: The best chess 1900-1999 in historical context. London: Gambit.

Burns, B. D. (2004). The effects of speed on skilled chess performance. Psychological Science, 15, 442-447.

Chabris, C. F., \& Hearst, E. S. (2003). Visualization, pattern recognition, and forward search: Effects of playing speed and sight of the position on grandmaster chess errors. Cognitive Science, 27, 637-648.

Charness, N. (1992). The impact of chess research on cognitive science. Psychological Research, 54, 4-9.

Charness, N., \& GerchaK, Y. (1996). Participation rates and maximal performance: A log-linear explanation for group differences, such as Russian and male dominance in chess. Psychological Science, 7, 46-51.

Charness, N., Krampe, R., \& Mayr, U. (1996). The role of practice and coaching in entrepreneurial skill domains: An international comparison of life-span chess skill acquisition. In K. A. Ericsson (Ed.), The road to excellence: The acquisition of expert performance in the arts and sciences, sports, and games (pp. 51-80). Mahwah, NJ: Erlbaum.

Charness, N., Tuffiash, M., Krampe, R., Reingold, E., \& VasyuKOVA, E. (2005). The role of deliberate practice in chess expertise. Applied Cognitive Psychology, 19, 151-165.
Chase, W. G., \& Simon, H. A. (1973). The mind's eye in chess. In W. G. Chase (Ed.), Visual information processing: Proceedings (pp. 215281). New York: Academic Press.

DE Groot, A. D. (1965). Thought and choice in chess. The Hague: Mouton.

Divinsky, N. (1990). The Batsford chess encyclopedia. London: Batsford. Elo, A. E. (1965). Age changes in master chess performances. Journal of Gerontology, 20, 289-299.

Elo, A. E. (1986). The rating of chessplayers, past and present (2nd ed.). New York: Arco.

Frydman, M., \& LYNN, R. (1992). The general intelligence and spatial abilities of gifted young Belgian chess players. British Journal of Psychology, 83, 233-235.

GaIge, J. (1987). Chess personalia: A biobibliography. London: McFarland.

Glickman, M. E. (1995). Chess rating systems. American Chess Journal, 3, 59-102.

Gobet, F., De Voogt, A. J., \& Retschitzki, J. (2004). Moves in mind: The psychology of board games. Hove, U.K.: Psychology Press.

Graham, J. (1984). The literature of chess. Jefferson, NC: MacFarlane.

Holding, D. H. (1985). The psychology of chess skill. Hillsdale, NJ: Erlbaum.

HoWARD, R. W. (1995). Learning and memory: Major ideas, principles, issues, and applications. Westport, CT: Praeger.

HowARD, R. W. (1999). Preliminary real-world evidence that average human intelligence really is rising. Intelligence, 27, 235-250.

HowARD, R. W. (2001). Searching the real world for signs of rising population intelligence. Personality \& Individual Differences, 30, 1039-1058.

HowARD, R. W. (2004). A revealing picture of chess: 33 years of FIDE ratings and data compiled. Chess Life, 59, 8-10.

HowARD, R. W. (2005a). Are gender differences in high achievement disappearing? A test in one intellectual domain. Journal of Biosocial Science, 37, 371-380.

HowARD, R. W. (2005b). Objective evidence of rising population ability: Detailed examination of longitudinal chess data. Personality \& Individual Differences, 38, 347-363.

Mantanovic, A. (2000). Chess is chess [CD-ROM]. Budapest: Chess Informant.

Milojkovic, J. D. (1982). Chess imagery in novice and master. Journal of Mental Imagery, 6, 125-144.

Newell, A. (1973). You can't play 20 questions with nature and win. In W. G. Chase (Ed.), Visual information processing: Proceedings (pp. 283-308). New York: Academic Press.

NunN, J. (1999). John Nunn's chess puzzle book. London: Gambit.

O'Connell, K. J. (1976). The Batsford chess yearbook, 1975/6. London: Batsford.

Reitman, J. S. (1976). Skilled perception in go. Cognitive Psychology, 8, 336-356.

SaArILUOma, P. (1991). Aspects of skilled imagery in blindfold chess. Acta Psychologica, 77, 65-89.

SAARILUOMA, P. (1992). Visuospatial and articulatory interference in chess players' information intake. Applied Cognitive Psychology, 6, 77-89.

Schwarz, A. M., Schachinger, H., Adler, R. H., \& Goetz, S. M. (2003). Hopelessness is associated with decreased heart rate variability during championship chess games. Psychosomatic Medicine, 65, 658-661.

SunNuCKS, A. (1976). The encyclopedia of chess. London: Robert Hale. VAN DER MaAs, H. L. J., \& Wagenmakers, E.-J. (2005). A psychometric analysis of chess expertise. American Journal of Psychology, 118, 29-60.

Waters, A. J., Gobet, F., \& Leyden, G. (2002). Visuospatial abilities of chess players. British Journal of Psychology, 93, 557-565.

WHYLD, K. (1986). Chess: The records. Enfield, U.K.: Guinness.

(Manuscript received June 15, 2005; revision accepted for publication September 17, 2005.) 